\title{
Physiological and metabolomics analyses reveal the roles of fulvic acid in enhancing the production of astaxanthin and lipids in Haematococcus pluvialis under abiotic stress conditions
}

Yongteng Zhao ${ }^{1, a}$, Hailiang Xing ${ }^{1, a}$, Xingyu $\mathrm{Li}^{2}$, Shuxiang Geng ${ }^{3}$, Delu Ning ${ }^{3}$, Ting $\mathrm{Ma}^{3}$, Xuya $\mathrm{Yu}^{1, *}$

${ }^{1}$ Faculty of Life Science and Technology, Kunming University of Science and Technology,

Kunming 650500, China;

${ }^{2}$ The First People's Hospital of Yunnan, Kunming 650100, China.

${ }^{3}$ Yunnan Academy of Forestry, Kunming 650051, China

*Corresponding author:xuya_yu@163.com

Tel: $+086-871-65920548$

${ }^{a}$ Co-first author. 
Table S1

Gene-specific primers used for qRT-PCR; F: forward; R: reverse.

\begin{tabular}{|c|c|c|c|}
\hline Primer & Primer sequence $\left(5^{\prime}-3^{\prime}\right)$ & Annealing temperature $\left({ }^{\circ} \mathrm{C}\right)$ & Amplified fragment size (bp) \\
\hline$d x s \mathrm{~F}$ & GTCTCCGCACTCTTCACC & \multirow{2}{*}{57} & \multirow{2}{*}{299} \\
\hline$d x s \mathrm{R}$ & CCCACCCAGTACAACAAC & & \\
\hline chy $\mathrm{F}$ & AATAGAATATGGGCGAAGC & \multirow{2}{*}{55} & \multirow{2}{*}{147} \\
\hline chy $\mathrm{R}$ & CTGGGTGAGGGTGATGC & & \\
\hline$b k t \mathrm{~F}$ & CAATCTTGTCAGCATTCCGC & \multirow{2}{*}{61} & \multirow{2}{*}{174} \\
\hline$b k t \mathrm{R}$ & CAGGAAGCTCATCACATCAGA & & \\
\hline kas $\mathrm{F}$ & CACCCCACTCTGAACCAGGA & \multirow{2}{*}{58} & \multirow{2}{*}{120} \\
\hline kas $\mathrm{R}$ & GACCTCCAAACCCGAAGGAG & & \\
\hline $\operatorname{fad} \mathrm{F}$ & GTAGGTCACCACGTCCAGCC & \multirow{2}{*}{58} & \multirow{2}{*}{120} \\
\hline fad $\mathrm{R}$ & CTTGATAGGCATGCTGGGTGT & & \\
\hline $\operatorname{sad} \mathrm{F}$ & CCGAGCCCAAGCTTCTAGTG & \multirow{2}{*}{58} & \multirow{2}{*}{120} \\
\hline $\operatorname{sad} \mathrm{R}$ & TTTGCCTCCATGTAATCCCC & & \\
\hline
\end{tabular}

